\title{
¿SON LAS MUJERES OBJETO DE ESTUDIO PARA LAS CIENCIAS SOCIALES? *
}

\author{
María Jesús Izquierdo \\ (Facultad de Ciencias Políticas y Sociología \\ Universidad Autónoma de Barcelona)
}

Aunque a estas alturas se da por sabido que nuestro modo de conocer no es un producto autónomo, es bastante frecuente olvidar que este proceso tiene lugar en unas condiciones históricas y sociales dadas. También es habitual instalarse en un marco teórico y utilizar unos conceptos como si fueran los únicos posibles, o como si los conceptos únicamente nos permitieran conocer realidad, cuando lo que ocurre es que conocer es construir o reproducir realidad. Por ello, nuestro trabajo intelectual sólo es nuestro parcialmente. Somos un producto social que a su vez produce; en tanto que producto, reproducimos ideología, en tanto que productoras, construimos conocimiento. A fin de cuentas, las condiciones en que se realiza el trabajo nos vienen impuestas, y con ellas se nos impone también la capacidad y el modo de conocer.

Cuando decimos estudiar a «la mujer», el marco social en que la mujer se nos presenta como susceptible de convertirse en objeto de estudio es sexista. Nos hallamos instaladas en el cosmos ideológico de la diferencia sexual y con esa ideología, dentro de ella, producimos nuestro discurso. Al mismo tiempo, la conciencia de hallarnos sujetas a esa ideología, esa capacidad de mirarnos convertidas en objeto, es la garantía de que seamos sujetos y podamos producir conocimiento.

* A lo largo de este artículo se ha optado por aplicar el plural femenino de modo general, las terminaciones en as pueden referirse tanto al colectivo femenino como a colectivos mixtos. Sirva este ejercicio para sensibilizar sobre la práctica inversa de aplicar el masculino a colectivos mixtos. 
Con/dentro de la ideología del sexismo, y en nuestro papel de sujetos/objetos sociales, se nos proponen y tal vez nos hayamos propuesto un número de preguntas a cuya pertinencia intentará dar respuesta este artículo. Sirvan unas cuantas de ilustración:

- ¿Qué hacen las mujeres?

- ¿En qué trabajan?

- ¿Por qué se casan? mente?

- ¿Qué políticas hay que desarrollar para que se integren social-

- ¿Qué hay que hacer con ellas para que no las discriminen, ni las violen, ni las exploten, ni las ignoren, ni...?

- ¿Qué derechos se les niegan?

- ¿Coinciden sus derechos formales con sus derechos reales?

Es como si se supusiera que a las mujeres les pasa algo, como si en las mujeres algo andara mal. Hay algo en ellas que las sitúa en una posición desigual; si este "algo» que falla en ellas se cambia, cambiará su situación. Hay que hacer algo por ellas, hay que ayudarlas.

$\mathrm{El}$ interés por las mujeres se inicia cuando un número de hembras a las que, de una en una, se les daba el nombre de mujer, se aglutinaron en base al reconocimiento de que su semejanza sexual es socialmente significativa, y se nombraron a sí mismas, conformando con ese nombre un colectivo. Diciendo «nosotras, las mujeres», hicieron posible que el objeto «mujer», al que le pasan cosas, se convirtiera en sujeto político, que hace cosas. Ello ha comportado a su vez que se hayan convertido en objeto de interés social, y que ese interés se refleje en el ámbito de las ciencias sociales.

La comunidad de mujeres ha hecho de «las mujeres» un sujeto, porque éstas han roto el discurso sobre la feminidad al construir su propio discurso. Las mujeres han emergido como sujeto político en la resignificación de los hechos, o en la significación de aquellos hechos silenciados. De significadas han pasado a ser significantes. Sólo es una contradicción aparente que las mujeres sean objeto precisamente en el momento en que se convierten en sujeto, cuando dejan de asumir su existencia como un dato y empiezan a interrogarse sobre las condiciones de la misma, en tanto que colectivo unido por una forma común de opresión.

Las mujeres, en tanto que sujetos, están significando. A la supuesta rudeza de los varones en sus relaciones con las mujeres, que recibía el nombre de virilidad, ahora se la nombra con otras palabras: violencia sexual y malos tratos. 
A lo que antes se nombraba como entrega amorosa del ama de casa al cuidado de los suyos, ahora se le pone el nombre de explotación doméstica del ama de casa. No es que la mujer haya dejado de amar, ni tampoco que la mujer sea el único ser capaz de amor. Lo que señala el nuevo discurso es que la actual forma social en que las mujeres expresan el amor, las coloca en una posición de dependencia financiera respecto de aquellos a quienes aman, ¿es también lo que las mueve a amar?

Dentro del nuevo discurso, a lo que todavía llamamos buscar novio, se podria denominar buscar empleo. Detrás del novio llega el marido y con él, el establecimiento de un vínculo no sólo laboral, y sin embargo también laboral. A «salgo un momento a comprar tabaco» podría considerarse cierre empresarial. Y a pegársela con otra podría muy bien decirse economia sumergida del amor. La lista de resignificaciones podría hacerse interminable. La dejaremos en este punto porque no es el propósito del artículo, sino que únicamente nos interesa para hacer visible el problema.

\section{CONOCIMIENTO CIENTIFICO Y REALIDAD}

Pues bien, ese ponerle palabras a la vida es sacarla del ámbito de la naturaleza y meterla en la sociedad. Es al mismo tiempo, y por ello, superar las leyes naturales para entrar en la norma, las leyes que regulan a la sociedad. Se entra en el dominio humano cuando se regula, porque regular es hacer controlables las cosas, humanizar la naturaleza. Es mutar el dato en suceso, las esencias - aquello que forma parte de la naturaleza de las cosas-, en contingencias - aquello que puede ocurrir- sobre las que se puede intervenir. Es, en suma, el paso del realismo a la realización, donde el dato es el prerrequisito del suceso.

Pero entre el realismo y la realización media la conciencia, y en las ciencias sociales, como en la propia sociedad en que se desarrollan, son dos tipos de conciencia los que predominan: la conciencia positiva y la crítica.

Una aproximación puede calificarse de positiva o crítica en función de las implicaciones de lo que para unos son sus revelaciones y para otros sus velaciones. Una conciencia de las condiciones de existencia que dice fundamentarse en cómo son las cosas, sin considerar por qué las vemos así, qué sentido tienen, a qué fines sirve el modo en que son y se ven, o cómo han llegado a ser vistas de la manera en que lo son, es conciencia de la naturaleza. Territorio en que «los hechos» se organizan o engranan guiados por fuerzas conocidas y reveladas en una «ley científica», aunque 
no por conocidas más controlables por parte de la razón que las conoce. Ese reconocimiento de la regularidad y universalidad de los fenómenos naturales (y como una parte de ellos, de los sociales), los normaliza, para llegar incluso a moralizarlos, y de ese modo los fija, al hacer deseable su permanencia.

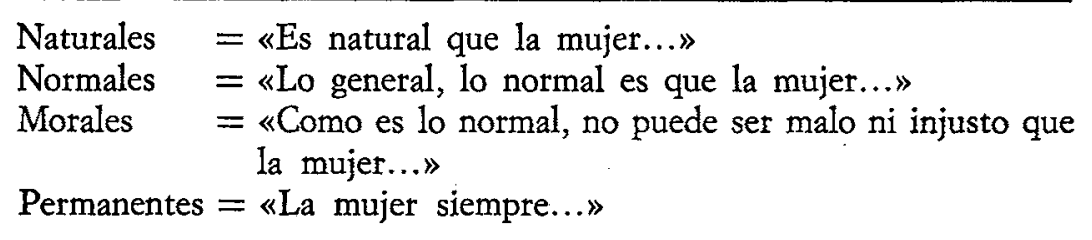

Es un fluir de la naturalidad a la inmutabilidad donde se desvanece el sentido moral porque no cabe la contingencia. Si las cosas son como son, si no pueden ser de otro modo, la norma ni siquiera es inmoral, en todo caso es amoral o paramoral. Si no cabe el sentido moral, no cabe el propio ser humano, porque el ser humano lo es porque está sujeto a la norma y la usa a su vez para sujetar.

La aproximación crítica, por el contrario, no se ocupa de los hechos, sino de las acciones; no contempla la vida en sociedad como un resultado, sino como un proceso; no está comprometida con la positividad, sino con las realizaciones; no se refiere a objetos, sino a sujetos que sujetan y a su vez son sujetados. Y la acción procede de la negación del hecho, revelando que quienes reivindican el cientifismo en base a su compromiso con los hechos, atribuyen factualidad a uno, y sólo uno, de los discursos posibles, porque lo que denominan becbos son discursos. Eso es lo que convierte en negativa a la vía de aproximación crítica. Para escapar al discurso por haberlo superado, la aproximación crítica comporta acción política, único criterio de falsación al que se subordina, y del que exige subordinación.

El discurso científico, sea crítico o positivo, es sólo uno de los discursos posibles. Reúne como requisito la objetividad, y se ve abocado a una actividad primera sin la cual no llega a diferenciarse del resto de los discursos, la «construcción del objeto». Cuando el objeto no se ha construido, cuando ni tan siquiera se pretende su construcción, cosa que sucede muy frecuentemente, la ausencia se enmascara con una supuesta neutralidad valorativa.

Se fantasea que adoptar una actitud distante es lo mismo que adoptar una actitud objetiva. La distancia, tomada como si fuera la separación, constituye para algunos la garantía de objetividad. Pero la distancia, como dice el refrán, amenaza con el olvido, lugar en que por dejarse de sentir, 
no cabe la posibilidad de conocer. Las condiciones que hacen posible la objetividad, aquellas que permiten realizar el objeto y reconocer el objeto que otros han realizado, pasan por adoptar como compañeras de camino la vigilancia epistemológica y la sospecha. ¿En qué condiciones surge nuestro propio conocimiento? ¿Qué es lo que no alcanza nuestra mirada? ¿Cuándo los propios ojos son un obstáculo para ver? Los ojos no nos sirven para ver porque la realidad está velada con ideología y la ideología se realiza en el acto de velar. Lo que se nos presenta como hechos sólo son apariencias; unas apariencias dotadas de la consistencia de lo real, realizadas.

\section{CIENCIA, IDEOLOGIA Y CONFUSION CONCEPTUAL}

Decíamos al principio de este artículo que se ha renovado la atención por «las mujeres», en muy buena medida, porque un colectivo se ha reconocido a sí mismo como tal y ha comenzado a producir el discurso de ese reconocimiento. Ya no es la esencia de la feminidad del siglo XIX y primera mitad del xx lo que despierta la atención, sino la situación social de las mujeres. Se ha pasado de un discurso de lo inmanente a otro de lo contingente. El cambio ha sido copernicano.

La paradoja es que si la precondición para el cambio es considerar su posibilidad, sujeto de cambio y objeto de estudio están condenados a negarse mutuamente. De ahí la importancia del paso de la inmanencia a la contingencia. Desde una aproximació crítica, el objeto de estudio «desigualdad sexual», es justamente la negación del sujeto de cambio «mujeres». No obstante, el error generalizado ha sido confundir lo uno con lo otro. Esas mujeres que se organizan políticamente para luchar no a favor de sus derechos —eso llevaría implícito la afirmación de la sociedad existente como una positividad-, sino contra la desigualdad sexual -en una negación de lo existente para cambiarlo-, están condenadas a desaparecer en la lucha en su condición de mujeres. Lo que las hace «mujeres», el contexto social en que nació el nombre que se dieron, la desigualdad sexual, es lo que hace posible que se transformen en sujeto colectivo. Una ciencia crítica es aquella que presenta/propone el camino que lleva a «las mujeres» a su desaparición como sujeto social, como el obrero desaparece con la disolución de la propiedad privada, el esclavo con la abolición de la esclavitud, o el negro con la superación del racismo. En ese momento, cuando mujeres/varones, obreros/propietarios, esclavos/patricios, negros/blancos, son objetos que se disuelven para emerger en su lugar suje- 
tos de conocimiento reconocidos los unos en los otros, habitando al otro lado de la ideología de la desigualdad.

El primer paso es la toma de conciencia. Un número de seres humanos empiezan a re-conocerse, porque se ven los unos en los otros, y la vivencia ya no es individual sino colectiva. Desde ese momento «ser mujer» ya no es la búsqueda de la identidad de "una» en "una misma», ya no se fundamenta en la inmanencia, en aquello que permanece en el ser, que es inseparable de sí misma. La identidad se produce al conocerse a «sí misma» en «las otras», es el paso del «ser» singular y único, al «ser social» plural y diverso. En tanto que conciencia de ser social, la mujer pasa de buscar su esencia a conocer su significado, y se descubre como una construcción social.

En ese proceso, no sólo es significada, sino que adquiere la capacidad de construir ella misma significados. El cambio en las condiciones de su existencia se halla desde ese momento asociado a la eliminación de la significación social de ser «mujer», y esa es una lucha política, un tomar partido. Cuando «la mujer» deja de ser socialmente significativa desaparece, ha sido destruida como significado. Sólo es significativa por ser desigual, por estar oprimida, por ser negada, pero la negación no es de ella, sino de una parte de cada uno de los humanos. Cuando cede la desigualdad, se pierde el significado de la mujer y se resignifica el ser humano, pues es la desigualdad sexual lo que le confiere existencia.

La aproximación, desde una ciencia social crítica, ve a la mujer como una ideología, detrás de la cual se agazapa la desigualdad sexual. Las mujeres cobran relevancia, se hacen significativas, porque cada día se realiza y renueva la desigualdad sexual. En consecuencia, el objeto ideológico que se nos propone no sólo difiere de nuestro objeto de estudio, sino que además constituye un obstáculo epistemológico. Para estudiar la «desigualdad sexual» se hace necesario construir conceptos que son el cemento y la arena con el que se produce el objeto, son esos conceptos los que permitirán desvelar la ideología al sustituirla por otro modo de conocimiento.

\section{CUANDO EL TORO YA NO VA AL TRAPO}

Cuando el toro se lanza contra el trapo que le ofrece el torero se le considera un animal valiente; sin embargo, no es el trapo sino el torero el que le robará la vida en la suerte, desgracia para el toro, de espadas. El que acabará destruyéndolo, el que le quita la vida es precisamente 
quien dirige sus actos con el capote. El dominio del torero sobre el toro: depende de su habilidad para esconderse tras el capote, que es la apa-. riencia del torero. Como las cosas no son lo que parecen, no tenemos. otro camino que empezar por la negación. Negación de esa apariencia: que se nos presenta como si fuera la propia realidad.

En la historia en general, y en la historia de la lucha contra la desigualdad sexual, así como en la historia del estudio de esa forma de desigualdad, hubo un primer período en que el capote ideológico tuvo la capacidad de distraer del verdadero objetivo.

El capote, el velo encubridor de las apariencias, se llamaba «diferencias: sexuales». Se suponía que en el origen de la desigualdad se halla una inferioridad. Las diferencias sexuales se presentaban en forma de jerarquía, y la jerarquía por ser sexual se naturalizaba. Con ello escapaba a toda valoración moral o política. Por otra parte, la vida social no se percibía más que como un reflejo de la vida natural. De esta manera, se suponía jerarquía sexual de los machos sobre las hembras de otras especies, esa jerarquía se traducía en jerarquía sexual de los machos sobre las hembras. de nuestra especie, y en jerarquía social de los varones sobre las mujeres.

Pues bien, ese capote de las «diferencias sexuales», en el que han quedado presos no pocos esfuerzos intelectuales, dio lugar a dos salidas: a) Si efectivamente son diferentes, pero nadie es superior a nadie, un sexo es lo que le falta al otro; y en su vida social las mujeres y los varones se complementan a través de la división sexual del trabajo. b) No hay diferencias, o las que hay no son significativas. Pero significativas era evidente que lo eran, lo que intentaban decir es que el alcance de las diferencias: no justificaba la significación social que tenían.

Aun cuando hoy todavía encontramos representantes de ambas corrientes, podemos decir que ya están superadas teóricamente. En la siguiente fase de este proceso de conocer para cambiar, la búsqueda de lo. inmanente -a través del estudio de las diferencias sexuales- quedó reemplazada por otro objeto: «la condición social de la mujer». En los distintos países occidentales se desarrollan lo que se denomina «Estudios de la Mujer», y en la academia se empieza a contemplar a «la mujer» como objeto de especialidad. El salto teórico es de una enorme trascendencia, pues el objeto de estudio ya no es vital, sino social. Se han creado las condiciones para que la «desigualdad sexual» pueda ser pensada. El objeto ha quedado desnaturalizado al vincularlo a factores de orden social, de entre los cuales, las condiciones de la división sexual del trabajo reciben un tratamiento preferencial.

Pero hay algo perverso en ese salto del conocimiento, porque suponeuna separación teórica respecto a los hechos naturales que realmente no se 
ha producido y que de hecho no es necesaria. Se toma a la mujer como un «hecho» y no como el objeto construido para estudiar el alcance social de las diferencias sexuales. Esto se hace visible en la aplicación de los conceptos de «patriarcado» y de «género».

\section{ALGUNOS PROBLEMAS EN LA UTILIZACIONN DE LOS CONCEPTOS «PATRIARCADO»Y «GENERO»: POR QUÉ «LA MUJER» NO ES OBJETO DE CONOCIMIENTO CIENTIFICO}

Como venimos diciendo, de estudiar las diferencias sexuales y su importancia se ha pasado a estudiar la situación de la mujer en la sociedad. Ello ha representado un esfuerzo conceptualizador en que las categorías centrales de análisis han resultado ser el "patriarcado» y el «género».

El concepto de patriarcado nos remite al carácter estructural de la desigualdad sexual, lo cual significa que ésta es inmanente al patriarcado, aun cuando el patriarcado únicamente sea un momento en la historia. Decir que la desigualdad sexual (orden de relaciones que se establece en función de la significación que se otorga en una sociedad, a las diferencias sexuales) es inmanente al patriarcado (orden social que se establece en función del parentesco $y$ en el que se denomina "padre» al ocupante de la cima de la jerarquía) es afirmar que la desigualdad sexual no puede desaparecer mientras la estructura social tenga un carácter patriarcal. Por tanto, estudiar el patriarcado es considerar aquellos factores que hacen de la desigualdad sexual una necesidad estructural. El concepto nos conduce a examinar las condiciones de la división sexual del trabajo, entendiendo la posición del cabeza de familia - la del patriarca- no tanto como un atributo personal, sino como un espacio social que requiere ser ocupado por alguien. El criterio de atribución del lugar del patriarca está siendo el de considerar padres a aquellos progenitores de sexo macho y de edad adulta, pues la variedad actual del patriarcado es una adultocracia sexista.

En tanto que el orden patriarcal no es un orden de la naturaleza, sino de la sociedad, características vitales como ser portador de unos caracteres sexuales y no de los otros, ser de una cierta edad y no de otra, no constituyen una determinación, sino un condicionante. En otras palabras, es posible - aunque no probable - la existencia de una sociedad patriarcal en que «los patriarcas» sean, por tomar un ejemplo, hembras añosas. De hecho, nuestra sociedad ha conocido un patriarcado distinto del actual, gerontocrático aunque no hembril. 
¿A dónde nos lleva esta argumentación? A señalar que en una sociedad desigual no se pueden tomar los derechos de «la mujer», en el sentido en que se toman los derechos del individuo, porque si todo individuo al que denominamos mujer gozara de los mismos derechos que el patriarca, sería como el patriarca es. Si el patriarca no se diferencia de su patrimonio no hay patriarcado. Las que ocupan el lugar social de mujeres no pueden luchar por los derechos de la mujer, porque en una sociedad patriarcal se es mujer, en tanto no se accede a los derechos del patriarca.

En cambio, se puede estudiar al «sujeto político mujer» tomándolo como un factor desencadenante de un cierto estado de la conciencia. «La mujer» es sujeto político, en la medida en que un número de seres humanos se reconozcan y se nombren a partir del significado que se da a sus caracteres sexuales «hembriles». En cambio, tomar como objeto de estudio a «la mujer» abre la posibilidad de reproducir ideología en lugar de producir conocimiento. Si la preocupación social es la mujer, la ocupación de las ciencias sociales es la desigualdad sexual que hace posible la existencia de la mujer, en la misma línea en que la preocupación social por el divorcio es ocupación de las ciencias sociales en la familia como objeto de estudio.

Es algo parecido a lo que ocurre en el caso del capitalismo; si el obrero, sea macho o hembra, emprende la lucha contra el clasismo y toma como estrategia la lucha por un salario justo, se está reivindicando como mercancía. La lucha por un salario indica el reconocimiento de que se es, en tanto que fuerza de trabajo, una mercancía. Sin embargo, cuando la única mercancía capaz de luchar para defender su propio precio, porque es la única capaz de conocer y conocerse, quiere obtener en el acto de la venta más de lo necesario para reproducirse como lo que es, al encarecerse puede poner en crisis la sociedad de mercancías. La aspiración a ser mercancía cara sólo se puede realizar en el capitalismo. En cambio, dentro del capitalismo no es realizable la vieja aspiración obrera de ser un sujeto de derechos, pues el único derecho real que se le puede conceder al asalatiado es el de comportarse como una mercancía. Es la propia estructura de la sociedad la que contiene la desposesión de los derechos del trabajador, en tanto es una estructura que se fundamenta en la existencia de la mercancía «fuerza de trabajo».

De similar modo, la mujer, considerada como producto estructural, no puede aspirar a gozar de derechos en una sociedad sexista, porque es justamente su falta de derechos la que convierte en sexista a la sociedad. En todo caso puede aspirar a la superación de ese orden social, patriarcal y sexista. Así, pues, como venimos insistiendo, en el contexto de una ciencia crítica del sexismo la mujer no es objeto de estudio, a la mujer no le pasa nada. El objeto de estudio es la desigualdad sexual, de la cual la 
mujer es un producto. Si tomamos a la mujer como objeto de estudio, reificamos un aspecto de la estructura patriarcal.

La dependencia entre hombres y mujeres es estructural en el mismo sentido en que las clases sociales forman parte de la estructura capitalista. El uno existe porque existe la otra. Posteriormente, esa dependencia estructural se traduce en dependencia personal, pero de la una no se deduce automáticamente la otra. Para que haya quienes ocupen el lugar de varón es preciso que haya quienes ocupen el lugar de la mujer. Es preciso que existan esos lugares y luego crear las condiciones que garanticen su ocupación. La condición de la existencia del lugar de varón en esta sociedad es la existencia del lugar de mujer. Si alguien se encuentra en una situación tal que no dispone de quien ocupe el lugar de $s u$ contrario/complementario, se encuentra en inferioridad de condiciones respecto a las demás, porque las demás sí están complementadas. Como persona tiene las de perder, porque no hay espacio social alternativo o adicional al que se produce cuando la sociedad está dividida en función del sexo. Sólo en vistas a otro orden social propiamente societario se puede pensar en la eliminación del sexismo y el establecimiento de relaciones que no impliquen dependencia subordinada de las unas respecto a los otros.

Junto al concepto de patriarcado se ha desarrollado otro para el estudio de la desigualdad sexual: el de género. Este artilugio conceptual es un instrumento de conocimiento con el que se separa con fines analíticos la desigualdad y las diferencias sexuales. El objetivo es determinar los aspectos sociales en que se manifiesta el sexismo, así como la intensidad de la determinación sexual. Sexos se reconocen dos -hembra y macho-, por lo que si un sujeto se encuentra indiferenciado desde el punto de vista de los caracteres sexuales, en lugar de tener denominación, o de constituir un espacio en blanco en el lenguaje pendiente de recibir nombre, se le otorga la denominación de macho o hembra en función de su apariencia, según su anatomía sea más parecida a una hembra o a un macho. Esta es la señal que luego permite ubicar a la gente en sociedad, atribuyéndole el género femenino o el masculino.

Lo que resulta paradójico es considerar las condiciones en que se empezó a utilizar el concepto de «género». Stoller y Money detectaron que un número de individuos mostraban el malestar de vivir en un cuerpo equivocado. Individuos de sexo macho se sentían mujer, individuos de sexo hembra se sentían varón, e individuos indiferenciados desde el punto de vista de los caracteres sexuales deseaban una definición de sexo que correspondiera a la forma en que se sentían. Ese «comportarse como», «sentirse como», es lo que comenzaron a denominar género; y en ese malestar expresado por sus pacientes interpretaron la falta de correspon- 
dencia entre sexo y género: entre las hembras que se sentían masculinos y los machos que se sentían femeninas. En casos de extremo malestar en que era claramente identificable que se había producido el cruce entre sexo y género se recomendaba practicar una operación de cambio de sexo (una castración en el caso de los machos), consistente en remodelar la anatomía para que el sujeto en cuestión tomara la «apariencia física» que socialmente se exige, dado que el sujeto no podía evitar la adopción de los comportamientos del género correspondientes al otro sexo, o no había modo de disuaditlo para que lo hiciera.

En resumidas cuentas, es importante recordar que en su génesis el concepto de género no ha sido desarrollado desde una perspectiva crítica del sexismo. Por el contrario, en sus primeras aplicaciones conducía a realizar una aproximación a las secuelas personales del sexismo, el cual perseguía la «integración» de las conductas disidentes por la vía del «si no hemos conseguido que siendo-hembra-actúes-como-una-mujer/siendo-macho-actúescomo-un-varón, vamos a hacer que "parezca" que lo eres». Es inteligible que sucediera algo así, la dictadura sexo/género es mucho más importante para el orden social patriarcal que la integridad física de las personas, pues la legitimidad de ese orden se fundamenta en la «naturalidad» con que las hembras ocupen la posición de amas de casa y los machos la de responsables financieros de la familia. No obstante, y a pesar de sus orígenes, este concepto ha resultado sumamente útil para estudiar las condiciones de producción y reproducción del sexismo, así como sus fisuras y contradicciones.

Desde la perspectiva de las ciencias sociales consideradas como ciencias independientes, la separación analítica «sexo/género» implica considerar el «sexo» como variable independiente: variable porque sexos hay dos (hembra/macho) e independiente porque el sexo no depende de factores sociales o psíquicos, sino orgánicos (hormonales, genéticos). En cuanto al «géneto», en cambio, hay tres posibilidades: masculino, femenino y neutro. El tratamiento que requiere es el de variable de rango medio, dependiente en unos casos y en otros independiente. Cuando se trata como variable dependiente, se busca estudiar los factores que inciden en que se produzcan los estereotipos, modelos y espacios sociales de género. Cuando se trata como independiente, se está estudiando el modo en que esos estereotipos, modelos y espacios, inciden en los comportamientos sociales de los individuos.

Evidentemente, desde una perspectiva que asuma la inseparabilidad de las ciencias en naturales y sociales, sexo y género son consideradas variables independientes y dependientes a la vez. Si las características físicas condicionan nuestra existencia en sociedad, marcando límites a lo que 
podemos hacer y al modo en que podemos hacerlo, nuestro ser físico, a su vez, es objeto de las condiciones sociales en que se produce nuestra existencia. La proporción de grasa/músculo, por citar un ejemplo, no depende sólo de factores genéticos y hormonales (sexuales), sino del régimen alimenticio y el tipo de actividades físicas que se desarrollan, factores todos ellos de carácter social (género). Dicho de otro modo, la separación analítica entre sexo y género no significa que se supongan separadas naturaleza y cultura, ni que sea realmente posible separar lo natural de lo cultural, puesto que en definitiva no somos otra cosa que animales de naturaleza cultural.

En todo caso, si lo que se pretende es estudiar la desigualdad sexual, la mujer y el varón no son datos, hechos, apriorismos, sino el resultado de la incidencia del sexismo sobre los machos y sobre las hembras humanas en una sociedad dada, porque no existe un género transcultural. El sexo hembra/macho se toma como variable independiente y se intentan explorar las condiciones de la existencia de las unas y los otros. El resultado de esta aproximación es hallar que ciertas características, intereses, formas de participación en la producción de la existencia, se presentan con una frecuencia muy elevada entre las hembras (ser ama de casa, tener ingresos bajos o no tenerlos, etc.); otras se presentan con elevada frecuencia entre los machos; y un tercer grupo de características, intereses, formas de participación en la producción de la existencia, se distribuyen homogéneamente entre hembras y machos, lo cual indica que no están sometidos a la división sexual.

Se llama «mujeres» a las hembras que participen de los atributos culturales comunes entre las hembras, y «varones» a los machos con las. características que aparezcan como atributos comunes entre los machos. Hallamos, además, colectivos de individuos en los que se ha roto la conexión sexo/género, bien porque siendo hembras presentan atributos socialmente considerados masculinos, bien porque siendo machos presen$\tan$ los atributos que en una sociedad dada se atribuyen a las hembras, bien porque sus atributos no han recibido definición de género y pertenecen a lo que podríamos considerar «neutro» desde el punto de vista del género.

Por este camino se pone de manifiesto que los géneros son mutuamente excluyentes, es decir, los espacios sociales, los lugares que se pueden ocupar en la división sexual de la sociedad, impiden la ubicuidad. No se pueden ocupar a la vez los espacios femeninos y los masculinos, y las personas que aparentemente ocupan ambos espacios (machos o hembras que en la familia son los ganadores del pan y hacen las tareas domésticas, p.e.) no cubren las exigencias sociales mínimas que ello comporta. Esta cons- 
tatación es la que conduce a reconocer que «lo femenino» y «lo masculinos forman parte de la estructura de la sociedad, y que una sociedad sin desigualdad sexual es una sociedad sin géneros, donde cada individuo desarrolla sus potencialidades sin que haya una predefinición de lo que puede hacer o no hacer en función de cual sea su sexo.

Una práctica muy habitual es usar indistintamente los términos «sexo» y «género». Allí donde antes se hablaba de la desigualdad de sexo ahora se habla de la desigualdad de género, pero en realidad se está haciendo referencia a las mismas cosas, pues, como decíamos, se continúan tomando a las mujeres y a los varones como apriorismos. En cambio, sólo tiene sentido utilizar el concepto de género si partimos de la base de que sabemos diferenciar a los machos de las hembras, y lo que queremos averiguar es qué quiere decir ser mujer o varón, a través de reconocer los rasgos del «género masculino» y del «género femenino», y detectar la intensidad con que uno y otro género se asocian a uno u otro sexo. Ambos sexos $y$ ambos géneros son necesariamente objeto de estudio, y el resultado final será el reconocimiento de la «mujer», pero también el del «varón», porque el uno sin el otro no són inteligibles.

Las combinaciones posibles entre sexo y género son como se presentan en el siguiente cuadro, siendo las más reconocidas las que dan lugar a la «mujer» y el «varón», el resto no reciben denominación, porque bajo la dictadura del género no se admite su posibilidad.

\begin{tabular}{lccc}
\hline & \multicolumn{2}{c}{ Género } \\
\cline { 2 - 3 } Sexo & Femenino & Masculino & Neutro \\
\hline Hembra & mujer & \\
Macho & & varón \\
Indiferenciado & & & \\
\hline
\end{tabular}

Pero, como avanzábamos al final del apartado anterior, en el último salto teórico (el que ha conducido a utilizar los conceptos de «patriarcado» y de «género») hay algo perverso, o por lo menos se produce el riesgo de la perversión, al desviarse del fin para el que estos conceptos se instalaron en la teoría. Ambos contribuyen a separar analíticamente las diferencias sexuales de las consecuencias sociales que tienen las mismas en forma de desigualdad sexual. La mujer y el varón, contemplados desde esta perspectiva, ya no son un hecho, un dato, sino algo que se construye socialmente, un resultado. Si son un resultado $-\mathrm{y}$ no un principio-, los 
conceptos de sexo y género son los que nos permiten llegar a él. Sin embargo, se confunde cotidianamente la anatomía con la geografía de la desigualdad sexual, como si existiera una coincidencia radical entre la una y la otra. Cuando se toma a la mujer como objeto de estudio, como punto de partida, se está confundiendo el sexo con el género, se está suponiendo que toda hembra es mujer y todo macho varón, como si el nexo existente entre sexo y género fuera determinista. Para estudiar la desigualdad sexual es preciso ver el modo en que pertenecer a un cierto sexo origina una posición diferente en la sociedad, debido al significado social que se le da a cada sexo.

Los conceptos «sexo» y género" nos permiten separar las diferencias sexuales de la desigualdad sexual y nos permiten a su vez detectar la desigualdad de género. En otras palabras, separando analíticamente el sexo del género y la desigualdad sexual de la desigualdad de género, es posible reconocer que en el patriarcado se producen dos tipos de jerarquía: la de los machos sobre las hembras, que da lugar a la desigualdad sexual; y la de los estereotipos, modelos y espacios masculinos respecto a los femeninos, que da lugar a la desigualdad de géneto. Puede verse, además, que la clasificación sexual condiciona nuestra asignación de género, pero es con el género como se nos atribuye un espacio en la sociedad. En otras palabras, el ama de casa no está marginada ni negada por ser hembras quienes generalmente ocupan ese lugar en la división sexual del trabajo, sino que las hembras están negadas por ser amas de casa. Si un macho ocupa el lugar de ama de casa, se verá negado y marginado por ocupar ese lugar como lo está la hembra que lo ocupa, aunque hay que subrayar que a esa situación se le sumará el rechazo social por la transgresión del orden patriarcal que supone el hecho de que un macho ocupe el lugar de ama de casa.

Al separar analíticamente el sexo del género, es posible constatar que el sexo en sí mismo no es causa de desigualdad social, sino que es la posición de género la que lleva implícita la desigualdad. Es constatable que un macho también puede estar sometido a la desigualdad de género, en la medida en que ocupe una posición social correspondiente al género femenino, y que su sometimiento a la desigualdad procede precisamente de ocupar ese espacio social del género.

Lo que en definitiva permite esta construcción conceptual es descubrir la existencia de desigualdad de sexo y desigualdad de género, y la casi completa coincidencia de la una con la otra. Esa coincidencia únicamente se rompe en las transgresiones a la norma hembra/femenina $=$ mujer, macho/masculino $=$ varón. La hembra que transgrede esa norma puede estar sometida a la desigualdad de sexo porque éste actúa a modo de 
estigma, pero no a la de género, puesto que al ocupar espacios sociales masculinos ha cruzado la frontera de la desigualdad, «de-generándose». De igual modo, el macho que comete la transgresión no se hallará sometido a la desigualdad de sexo, porque el estigma de su apariencia física le preserva de esa contingencia, mientras que en cambio se verá sometido a las consecuencias de la desigualdad de género, puesto que ha cruzado la frontera de la desigualdad de género en la dirección contraria, siendo su «de-generación» una pérdida en la jerarquía de los géneros. Cuando a la hembra transgresora, «de-generada», se le denomina mujer, se la está reduciendo a su sexo, puesto que se le denomina mujer aunque no se ajuste a las características del género femenino en su sociedad. De igual modo ocurre cuando al macho transgresor se le continúa denominando varón. Eso supone usar los términos mujer y varón como substitutivos de hembra y macho. La consecuencia es que el género queda disuelto analíticamente en el sexo y la desigualdad de género en la desigualdad sexual. De este modo, pierde todo sentido teórico el concepto de género.

\section{DEL CONOCIMIENTO A LA ACCION:}

\section{LA VIA TRANSDISCIPLINARIA}

Abríamos estas páginas señalando el compromiso con lo que denominamos aproximación científica crítica, el cual definíamos como aquella aproximación comprometida con la acción, los procesos, las realizaciones. Ese compromiso con las realizaciones implica contemplar la realidad como la negación, el obstáculo al proyecto. El proyecto se realiza cuando el conocimiento y la acción están asociados. En esa asociación es donde el conocimiento recibe su reconocimiento, al superar la negatividad realizando la teoría. Cuando se supera la realidad de la desigualdad sexual y la desigualdad de género, cuando se realiza el proyecto de superar la desigualdad social, en cuya base se encuentran esas dos formas de desigualdad, es la propia teoría la que se ha realizado, porque ha favorecido la realización de la aspiración política; y la especulación se convierte en ciencia, porque la teoría es «un hecho». El camino está abierto y el proceso puede continuar. El hecho vuelve a ser negado y esa negación conduce a una nueva teoría realizadora, pero aunque sepamos que el camino está abierto, no sabemos a dónde nos lleva más allá de la superación de la desigualdad social, porque el camino se construye al caminar.

La aproximación crítica, en su compromiso con las realizaciones, lleva a su vez implícito un compromiso con la superación de las parcelas disci- 
plinarias. Para que el conocimiento conduzca a la actuación, su alimento básico es la aspiración política. La aspiración política, por su parte, queda alienada en la parcelación disciplinaria y en la parcelación paradigmática de cada disciplina. Queda alienada en la parcelación disciplinaria porque el objeto científico es sólo una parcela del objeto político: perspectiva biológica, económica, psicoanalítica, anatómica, sociológica, etc. Queda alienada en la parcelación paradigmática de cada disciplina por la pluralidad de perspectivas dentro de cada una de ellas: visión mecanicista, organicista, relacionista/conflictiva, etc.

La acción política negativa necesita de una ciencia negativa unificada. Pero este proyecto es mucho más ambicioso que la mera interdisciplinariedad, porque es la opción del «juntos, no revueltos». Supone el conocimiento del objetivo político y el reconocimiento de cada disciplina como multiparadigmática, buscando la hermandad de paradigmas de una disciplina a otra. Cada aspiración política tiene el paradigma científico que permite realizarla o puede producirlo. Esa unión entre la acción política y el paradigma científico, que denominamos transdisciplinariedad, es lo que consideramos la respuesta consecuente de una ciencia crítica comprometida con la realización del ser humano, y por tanto superadora de alienación, en la que se enraizan todas las formas de desigualdad social.

Mayo de 1988 